\title{
Applications of ICT Services for E-Government
}

\author{
Jiantong Cao and Zhike Che \\ School of Economics and Management, Beijing University of Posts and \\ Telecommunications, Beijing 100876, P.R. China tony000@263.net
}

\begin{abstract}
ICT (Information and Communication Technology) has been recognized as one main revenue stream for telecom industry, and widely be used for lots of fields, such as government, automobile, health and some others. This article, which aims to explore ICT service for e-government application, focuses on the current products \& services provided by telecommunication operators. After studying Verizon business, NTT DATA, Orange, BT and Tsystem, which are the top ICT service providers in government market. This article describes the general government market, and then, followed by the analysis of the current products \& services which can be cataloged by voice, data, IT and BPO. And the discussion will be made on each service. Finally the article shows the important of ICT in the e-government and potential application and service for telecom operators.
\end{abstract}

Keywords: E-government, ICT, Telecom operator

\section{INTROUDCTION}

In order to provide better service for the citizens and businesses, more and more governments take advantage of information and communication technologies (ICT) to complete the e-government strategies, so that eliminate existing bureaucracy and therefore achieve significant economic and operational efficiencies. It is obvious that governments and governmental institutions are the most complicated organizations in the society providing the legal, political and economic infrastructure to support the daily needs of citizens and businesses [1]. The internet was been seen a convenient and cost-saving channel for governments delivering information and providing online transactions.

In the past, the implementation of e-government was divided into two parts: IT infrastructure and telecommunication services, which were provided separately by IT companies and telecom operators [2]. With the convergence of IT and communications, the distinction between IT and telecom became vague [3]. The IT companies showed great interests in ICT, from 2002, Britain Telecom (BT for short) began ICT strategy as a innovative service [4]. Nortel and Microsoft allied for Communication convergence. All these action can be seen as the sign of convergence. The Figure 1 is the general ICT capability [5]. 


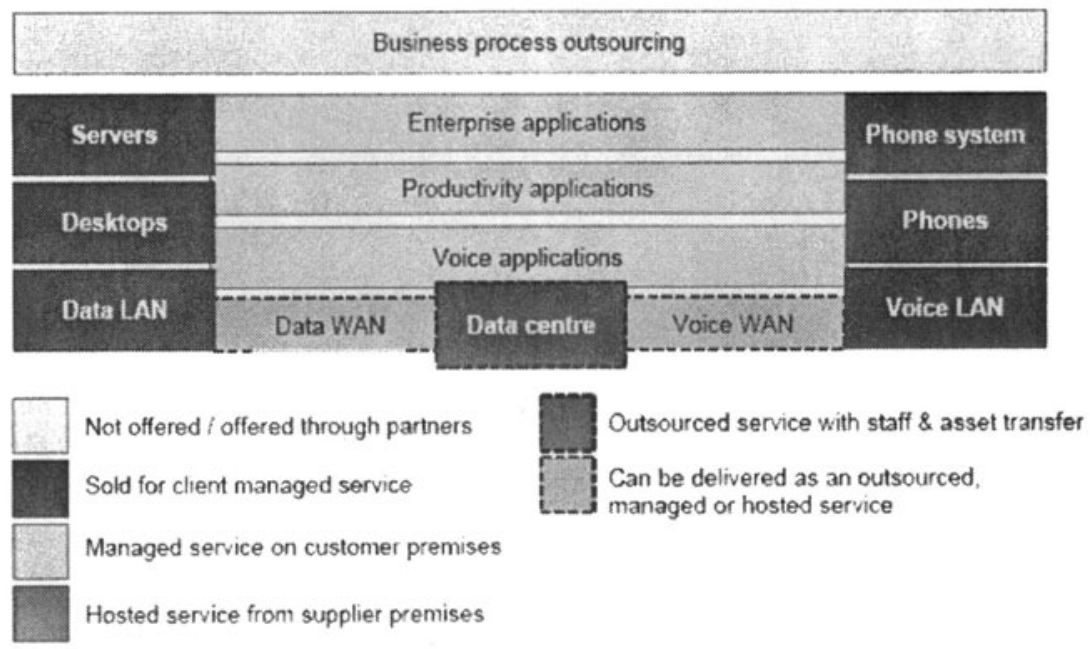

Source: KPN, Ovum

Figure 1. ICT Capability Map

So, it's possible for government to create a single, uniform, high-capacity network that allows data to flow quickly and reliably alongside telephony, helping to enhance productivity and reduce operating costs. In addition, a converged network makes it simple and affordable to integrate new applications and embrace new approaches such as flexible working.

At this moment, the governments face a choice: which would be better provider of ICT service? Telecom operators or IT companies? In this paper, I would like to analyze the ICT service for e-government provided by Telecom operators, and the suggestion would be given.

\section{EXISTING ICT SERVICE FOR E-GOVERNMENT}

In this chapter, the authors carefully analyze the international telecom operators which include: NTT DATA, Deutsche Telekom (T-Systems), BT, Verizon business, AT\&T. These companies are all the top-level ICT providers globally, of course, also perform excellent in e-government application.

Government is the main customer. Here the government involves central government, state and local government and defense department. The Table 1 showed the importance of government for the operators. 
Table 1. ICT Department of Operators for e-Government

\begin{tabular}{|c|c|l|l|c|}
\hline T-system & AT\&T & Verizon & BT & $\begin{array}{c}\text { NTT } \\
\text { DATA }\end{array}$ \\
\hline $\begin{array}{l}\text { Real ICT } \\
\text { for public } \\
\text { sector }\end{array}$ & $\begin{array}{l}\text { AT\&T } \\
\text { government } \\
\text { solution }\end{array}$ & $\begin{array}{l}\text { Verizon Federal } \\
\text { Verizon state, } \\
\text { local } \\
\text { government } \\
\text { \& defense }\end{array}$ & $\begin{array}{l}\text { Public sector (central, } \\
\text { local, defense \& } \\
\text { devolved } \\
\text { government) }\end{array}$ & $\begin{array}{l}\text { Public } \\
\text { administration } \\
\text { sector }\end{array}$ \\
\hline
\end{tabular}

ICT services provided by telecom operators for government can be categorized into:

\section{I System Integration Service}

As system integrators, operators can help government departments plan and harness the right technology and networks that are critical in facilitating agile, secure, reliable and compliant information management systems. These system integrations include design of project, purchase, implementation and adjustment of software and hardware, and also the after-sales service under contract.

I Operators provide network telecommunication integration. Many authorities today have a patchwork of different networks, with several carriers and incorporating a wide variety of applications and requirements. The result: high cost of maintenance and which includes WAN/ LAN/ VPN equipment, network security, PBX and so on. These services were quite meet the strength of telecom operators.

II Network application integration embraces call center, video communication (conference and inspect) and network security application. Call center has been one of important channels for government to provide service for citizen and business. BT help the Britain government built call center, so as to improve efficiency and cut cost [6]. Security, a genuine IT service, is another important ICT service for government. Verizon business bought NetSec (a IT security company), so that can serve government customers [7].

III For the e-government, telecom operators provide the industrial services: portals and collaboration.

E-government mainly is seen as a way of dealing with local, national and federal authorities through the Internet, saving time and travel and simplifying and speeding up procedures. T-Systems can build Internet Portals for government, so that government agencies are offering citizens and businesses a better service [8].

The government's IT system is so complex that the collaboration between different departments poses a key challenge for the government. BT offer Shared services that can allow several organizations to operate as a single entity based on standard good practice and sound performance management [6]. So it can be a key enabler of effective, efficient government.

Integrating and re-designing these above essential processes to achieve optimum efficiency has been made easier. 


\subsection{Outsourcing Services}

A range of Public sector organizations are increasingly looking at outsourced solutions as a way to reduce internal costs and improve service delivery [9].

The benefits of outsourcing are clear - particularly in the case of ICT, which is potentially expensive and labor intensive when dealt with 'in-house'. By enlisting the help of a trusted operator, government departments can benefit both from specialist expertise and technology, and significant economies of scale. BT is currently working on significant outsourcing projects for Department for Work and Pensions (DWP) and HM Revenue \& Customs [6].

The outsourcing can also be cataloged by two kinds:

I. Network telecommunication, the government outsources management of core switch equipments, core routers, WAN switches, gateway and other related network equipments. The operators were in charge of the maintenance and operation.

II. Network application. This mean the government outsource maintenance and management of call center, video communication (conference and monitoring)

By managing outsourced functions, telecom operator enables government and allied organizations to concentrate on core activities and achieve significant savings through more effective use of internal resources.

\subsection{Professional Services}

The telecom operators can provide integrated solution for the government, which include the network communication, network application as requested. These services mainly include:

I Backup and Restore service involves data protection of remote servers and desktops delivers data backup from multiple locations. Government's information is backed up at remote sites thereby lowering the probability of disaster-related data loss. So that keeps the critical business operation up and running. BT Datasure is a simple, easy and cost-effective solution for backing up server data, applications and operating systems [6].

II Management service

Harnessing technology to create more responsive and inclusive government can help to achieve higher levels of citizen satisfaction and deliver efficiency gains [7].

CRM, as a tool of higher citizen satisfaction, plays an integral part in providing effective service delivery in government, thanks to the telecom operators, like BT, TSystems. This comes to true.

Moreover, T-Systems deliver financial management [8]. With an integrated budgeting and accounting system from T-Systems, authorities can control the costs.

AT\&T offers Lifecycle Management, which includes software updates, protocol modifications and/or changes in hardware configurations enable optimum performance of government network [10].

Public Key Infrastructure (PKI), e-legal transaction also belongs to this service. 


\subsection{Knowledge Support}

The operators have many experts of rich experience, so they can provide expertise for governments and improve the development of e-government.

Network Planning and Consulting service, include network planning, network optimizing consulting, business procedure planning, IT system planning, IT system test and risk assessment, business continuity, as well as Disaster Recovery。

Verizon business gives government invaluable advice and analysis from qualified experts. Working with Strohl Systems, the professional services consultants can help government improve their existing business continuity plan or devise and implement a brand new plan designed to readily accommodate rapid advances in technology [7].

\subsection{Mobile Government}

Everything goes to mobile. Mobile is expected to be the next gold mine for ICT. Wireless technology can help government make more efficient use of its resources. By offering maximum flexibility and mobility, it can help enable staff to be productive and responsive, anywhere, anytime - ideal if they regularly visit other agencies or departments. In addition, wireless technology can free up valuable 'fixed' office space and offer a more versatile working environment.

Based on high-speed Wireless Local Area Networks (WLAN), WiFi technology allows you to connect a range of devices - PCs, Laptops, PDAs, and mobile phones to the Internet without using cables or wires. This enables staff to exchange voice and data, and access vital information and applications, at high-speed, whenever they're in range of a wireless hub.

BT, T-Systems Verizon business and orange all began delivering mobile application for government. This trend would continue, and affect the future of ICT.

\section{TELECOM OPERATORS WOULD PLAY A BIG ROLE IN E- GOVERNMENT}

From the above products, it's clear that the operators have showed significant advantage in E-government market. Following is the advantage of operators for ICT product, when comparing with the traditional IT companies.

Better understand on network. Public telecommunication network is the infrastructure of ICT. It's convenient for operators expand ICT service for government. Lots of products are network-central.

Network effect meets the characteristic of government. Operators manage a whole network around the country even extending abroad. Accordingly the government scattered all over the country. The traditional IT companies couldn't eliminate this gap between.

It's not a long time for operators to provide ICT for government. And the government's IT request is differ from the telecom demand. So challenge facing the operators is still heavy: first is the talent, there are too many network experts, but lack 
of real ICT expert. Second is the industrial experience. Today's ICT service is much more complex and customized. Lack of experience pose a key challenge for telecommunication companies.

At present, the telecom operators try their best to exert their strength and avoid the weakness. BT Called their ICT service as networked IT. So do other operators.

\section{CONCLUSIONS}

From the above analysis, we will propose some suggestion for the government and telecom operators.

For the governments, they should rethink the former impression of telecom operators. Under heavy financial pressure and shortage of experienced ICT staff, outsourcing should be regarded as an invaluable method for government, so that they can concentrate on the core-business, and build an efficient and cost-effective egovernment.

For the telecom operators, as newcomers in IT field, are expected to offer integrated IT service to the total ICT solution. Firstly Partnership, merger are both important path to improve operators' IT strength. Secondly the operators have served government for many years; however, they are required to explore government deeply, especially comparing with IBM, SAP, big IT companies.

\section{REFERENCES}

1. A. Bouguettaya, A. Rezgui, B. Medjahed, and M. Ouzzani, Internet Computing Support for Digital Government, Practical Handbook of Internet Computing, eds. M.P. Singh (CRC Press, 2004).

2. S. He, The challenges of e-government development in China, EBchina (2006), pp.45.

3. D.J. Leu, Jr. Charles, and K. Kinzer, The Convergence of Literacy Instruction with Networked Technologies for Information and Communication, Reading Research Quarterly. Volume 35, Number 1, pp.108-127, (2000).

4. Annual report, BT (2002).

5. X. Liu, Broadband, Wireless ICT-the Revelation of BT transition telecommunication world 2005 10th (2005), pp.1009-1564.

6. Chris Lewis, Katy Ring and Jan Dawson, ICT strategy for Telecos, by OVUM report (unpunished, 2005), pp.29.

7. www.bt.com (Assessed Apr.20, 2007).

8. www.verizonbusiness .com (Accessed Apr.20, 2007).

9. www.tsystems.com (Accessed Apr.20, 2007).

10. M. Hancox and R. Hackney, Information technology outsourcing: conceptualizing practice in the public and private sector, in Proc. of the 32nd Annual Hawaii International Conference System Sciences, Volume 7 (Maui, HI, 1999).

11. www.att.com (Accessed Apr.20, 2007). 